\title{
Depression severity moderates the relation between self-distancing and features of emotion unfolding
}

Citation for published version (APA):

Resibois, M., Kuppens, P., Van Mechelen, I., Fossati, P., \& Verduyn, P. (2018). Depression severity moderates the relation between self-distancing and features of emotion unfolding. Personality and Individual Differences, 123, 119-124. https://doi.org/10.1016/j.paid.2017.11.018

Document status and date:

Published: 01/03/2018

DOI:

10.1016/j.paid.2017.11.018

Document Version:

Publisher's PDF, also known as Version of record

Document license:

Taverne

Please check the document version of this publication:

- A submitted manuscript is the version of the article upon submission and before peer-review. There can be important differences between the submitted version and the official published version of record.

People interested in the research are advised to contact the author for the final version of the publication, or visit the DOI to the publisher's website.

- The final author version and the galley proof are versions of the publication after peer review.

- The final published version features the final layout of the paper including the volume, issue and page numbers.

Link to publication

\footnotetext{
General rights rights.

- You may freely distribute the URL identifying the publication in the public portal. please follow below link for the End User Agreement:

www.umlib.nl/taverne-license

Take down policy

If you believe that this document breaches copyright please contact us at:

repository@maastrichtuniversity.nl

providing details and we will investigate your claim.
}

Copyright and moral rights for the publications made accessible in the public portal are retained by the authors and/or other copyright owners and it is a condition of accessing publications that users recognise and abide by the legal requirements associated with these

- Users may download and print one copy of any publication from the public portal for the purpose of private study or research.

- You may not further distribute the material or use it for any profit-making activity or commercial gain

If the publication is distributed under the terms of Article $25 \mathrm{fa}$ of the Dutch Copyright Act, indicated by the "Taverne" license above, 


\title{
Depression severity moderates the relation between self-distancing and features of emotion unfolding
}

\author{
Maxime Résibois $^{\mathrm{a}, *}$, Peter Kuppens ${ }^{\mathrm{a}}$, Iven Van Mechelen ${ }^{\mathrm{a}}$, Philippe Fossati ${ }^{\mathrm{b}, \mathrm{c}}$, Philippe Verduyn ${ }^{\mathrm{d}, \mathrm{a}}$

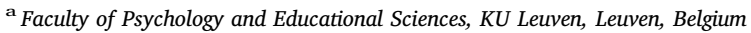 \\ ${ }^{\mathrm{b}}$ Inserm U 1127, CNRS UMR 7225, Sorbonne Universités, UPMC Univ Paris 06, UMR S 1127, Institut du Cerveau et de la Moelle, ICM-A-IHU, Social and Affective \\ Neuroscience (SAN) Laboratory \& Prisme Platform, Paris, France \\ ${ }^{c}$ AP-HP, Department of Psychiatry, Pitié-Salpêtrière Hospital, 47-83 Boulevard de l'Hôpital, 75013 Paris, France \\ d Faculty of Psychology and Neuroscience, Maastricht University, Maastricht, Netherlands
}

\section{A R T I C L E I N F O}

\section{Keywords:}

Emotion dynamics

Intensity profiles

Self-distancing

CES-D

Depression severity

\begin{abstract}
A B S T R A C T
Thinking about a negative event from a self-distanced (vs. self-immersed) perspective is associated with lower emotion intensity. However, it is unclear how self-distancing impacts emotion unfolding and whether individual differences in depression severity moderate this impact. We addressed this issue by examining the effect of selfdistancing on emotion explosiveness (i.e., steepness of the emotion response at onset) and accumulation (i.e., intensification of the response after onset) in participants differing in levels of depression. Participants adopted a self-immersed or self-distanced perspective while reading and thinking about manipulated negative social feedback. Both explosiveness and accumulation decreased when participants adopted a self-distanced perspective. Moreover, the effect of perspective taking on accumulation was especially outspoken for people with high levels of depression severity.
\end{abstract}

\section{Introduction}

People are inevitably confronted with negative events and emotions in their life. One way people deal with this is by reflecting on these negative experiences in order to make sense of them (Papageorgiou \& Wells, 2001). However, despite that self-reflection has been shown to decrease the intensity of negative emotions (e.g., Wilson \& Gilbert, 2008), the opposite has been found as well (e.g., Nolen-Hoeksema, Wisco, \& Lyubomirsky, 2008).

To account for these seemingly contradicting consequences, a distinction has been made between two types of perspectives one can adopt while self-reflecting: a self-immersed versus a self-distanced perspective (Ayduk \& Kross, 2010). When adopting a self-immersed perspective, the event and associated emotions are (re-)experienced from a first person perspective, visualizing them through one's own eyes (Nigro \& Neisser, 1983). When adopting a self-distanced perspective, the event and associated emotions are (re-)experienced from a thirdperson perspective, visualizing them through the eyes of an external observer or "fly on the wall" (Robinson \& Swanson, 1993).

In both healthy and depressed populations, self-distancing appeared to be associated with reduced levels of negative emotions (Ayduk \& Kross, 2010). In particular, in contrast to adopting a self-immersed perspective, self-distancing led healthy individuals to experience decreased levels of emotional and physiological reactivity (Ayduk \& Kross, 2008) as well as a reduced amount of intrusive ideation (Ayduk \& Kross, 2010), and to be buffered against psychological stress (Denny \& Ochsner, 2014; Penner et al., 2016) and depressed affect (Kross \& Ayduk, 2008). Similarly, people with major depressive disorder experienced reduced negative affect and depressogenic thought accessibility when reflecting on negative experiences from a self-distanced perspective (Kross, Gard, Deldin, Clifton, \& Ayduk, 2012). Interestingly, the impact of self-distancing on negative emotions linearly increased with levels of depression severity (Kross \& Ayduk, 2009), suggesting that especially people suffering from more severe forms of depression might benefit from adopting a self-distanced perspective.

Although self-distancing has been shown to be an effective way to influence negative emotions, so far almost all prior studies have examined this without considering a key component of emotional responses: time. Indeed, emotions are processes that unfold over time, and studying their dynamic nature is critical for a better understanding of them (Frijda, 2007; Verduyn, Van Mechelen, Tuerlinckx, Meers, \& Van Coillie, 2009), as well as of their link with affective disorders and psychological wellbeing (Houben, Van Den Noortgate, \& Kuppens, 2015). Moreover, time is at the heart of dominant models of emotion regulation (Gross, 2015; Koole, 2009) and it has been argued that the modulating potential of regulation strategies may change as the

\footnotetext{
* Corresponding author: Tiensestraat 102 box 3713, 3000 Leuven, Belgium.

E-mail address: maxime.resibois@kuleuven.be (M. Résibois).
} 
emotion unfolds (Kalokerinos, Résibois, Verduyn, \& Kuppens, 2017). One notable exception of research on self-distancing taking a dynamic approach is a study by Verduyn, Van Mechelen, Kross, Chezzi, and Van Bever (2012), who found that adopting a self-distanced perspective shortens the duration of emotional experience. However, this study focused on emotion duration only and did not examine the influence of self-distancing on the pattern of emotion unfolding.

Research on emotion dynamics found that emotions unfold across two phases (Davidson, 1998; Koole, 2009) with two associated dynamic features (Kuppens \& Verduyn, 2015; Résibois, Kalokerinos, et al., 2017; Résibois, Verduyn, et al., 2017): emotion explosiveness and accumulation. Emotion explosiveness (primarily coming to the fore during the onset stage of emotion unfolding) reflects whether the emotional episode has a steep versus a gentle start. Emotion accumulation (primarily coming to the fore during the offset stage of emotion unfolding) reflects whether emotion intensity increases over time versus goes back to baseline. As emotion explosiveness and accumulation have been found to be the dominant sources of variability in emotion unfolding (Résibois, Kalokerinos, et al., 2017; Résibois, Verduyn, et al., 2017; Verduyn et al., 2009; Verduyn, Van Mechelen, \& Frederix, 2012), the impact of self-distancing on emotion dynamics can be best understood by examining how adopting a self-distanced (vs. self-immersed) perspective modulates these two key temporal features.

The aim of this study is thus to examine the impact of perspective taking on emotion explosiveness and accumulation. As emotion regulation strategies are assumed to mainly influence the later rather than the earlier stage of emotion unfolding (Koole, 2009), we expect selfdistancing to especially lead to lower levels of accumulation and to a lesser extent to lower levels of explosiveness. Moreover, as the impact of adopting a self-distanced perspective on emotion intensity has been found to be especially strong amongst people suffering from more severe degrees of depression (Kross \& Ayduk, 2009), we expect that the impact of perspective taking on emotion unfolding will be especially strong for people with higher levels of depression severity.

To test these hypotheses, we induced negative emotions using a negative social feedback paradigm, and asked people to read and think about the presented feedback while adopting a self-immersed or selfdistanced perspective. Similar to Verduyn and colleagues (Kalokerinos et al., 2017; Résibois, Kalokerinos, et al., 2017; Verduyn et al., 2009; Verduyn, Van Mechelen, \& Frederix, 2012), we made use of the intensity profile tracking approach to collect data on emotion unfolding. This procedure, originally developed by Frijda and colleagues (Frijda, 2007; Sonnemans \& Frijda, 1994), consists of having people draw profiles reflecting changes in the intensity time course of recently experienced emotions.

\section{Method}

\subsection{Participants}

Participants were 70 (46 females and 24 males) native Dutchspeaking KU Leuven students (mean age: 22.57 years, $S D=4.27$ ) who provided written informed consent prior to the start of the study and received 15 Euros as compensation for their participation. The number of participants was based on a previous study examining the effect of spontaneous emotion regulation on the temporal features of emotion intensity, where 74 participants were shown to be sufficient to detect meaningful effects (Résibois, Kalokerinos, et al., 2017). ${ }^{1}$ The study was approved by the ethics committee of KU Leuven.

\footnotetext{
${ }^{1}$ According to a formal a priori power analysis (Faul, Erdfelder, Lang, \& Buchner, 2007) $\left(d_{z}=0.58\right.$, alpha $=0.05$, power $\left.=0.80\right)$, a sample of at least 26 participants could be needed for a paired-sample $t$-test (self-distanced vs. self-immersed). The effect size estimate $d_{z}=0.58$ is based on a meta-analysis of Webb, Miles, and Sheeran (2012).
}

\subsection{Materials}

\subsubsection{Center for Epidemiologic Studies Depression (CES-D) scale}

We measured participants' depressive symptoms that occurred during the week prior to the study by calculating the mean score ( $\alpha=0.85$, Mean $=0.60, \mathrm{SD}=0.36$ ) on a Dutch translation of the CESD scale (Radloff, 1977), which consists of 20 items (e.g., "I thought my life had been a failure") rated using a 4-point Likert scale, ranging from 0 (rarely or none of the time $(<1$ day)) to 3 (most or all of the time (5-7 days)).

\subsubsection{Social feedback}

Emotions were induced using a social feedback procedure (Bushman \& Baumeister, 1998; Eisenberger, Inagaki, Muscatell, Byrne Haltom, \& Leary, 2011) on an earlier performed task. The feedback consisted of a table of ratings on desirable traits (social, interesting, and honest), undesirable traits (stubborn, superficial, and naïve) and a general item reflecting whether the judge would like to have the participant as a friend. The negative feedback involved low scores on desirable traits and the item reflecting the wish of the judge to have the participant as a friend, and high scores on undesirable traits. Neutral feedback involved ratings close to the neutral scale midpoint for all feedback items. In total, participants received eight sets of negative, and eight sets of neutral feedback. Feedback appeared in one of two pre-specified orders with a maximum of two negative trials following each other. Feedback order was not related to either explosiveness $(p=0.70)$ or accumulation $(p=0.20)$, nor did controlling for feedback order alter any of the reported conclusions.

\subsubsection{Emotion intensity profile tracking method}

Participants reported on changes in negative affect by drawing an intensity profile with a computer mouse on a two-dimensional grid. Time was represented on the $X$-axis, with coordinates having a resolution of 780 pixels and being divided into two main parts. The first part, occupying one-third of the screen, represented the 30-second "reading the feedback" period, whereas the second part, occupying twothirds of the screen, represented the 60-second "thinking about the feedback" period. The intensity of participants' negative affect was represented on the $Y$-axis, with coordinates having a resolution of 510 pixels and being divided into seven intervals ranging from 'none' to 'very high'.

\subsection{Procedure}

Similar to Study 1 in Résibois, Kalokerinos, et al. (2017), the experiment consisted of four phases. In Phase 1 (duration: $20 \mathrm{~min}$ ), participants wrote short texts on pre-specified topics reflecting their life goals (e.g., "Describe what you would like to achieve in the next 10 years"). They were made to believe that these texts would be read by four judges, who would independently try to estimate their personality from these texts. Participants were further explained that the (supposed) judges would be deceived in thinking that each text was written by someone else, which would (supposedly) allow the experimenters to study the stability of the judges' first impressions.

In Phase 2 (duration: $20 \mathrm{~min}$ ), participants completed a number of questionnaires including the CES-D while the judges were supposedly estimating participants' personality based on their texts. In addition to the CES-D questionnaires measuring emotion regulation, personality and well-being were assessed (see Supplementary Information for the full list of questionnaires). Controlling for all these additional variables did not alter any of the conclusions we will further report and we will therefore leave these questionnaires aside in the remainder of the paper.

In Phase 3 (duration: $45 \mathrm{~min}$ ), participants were exposed to social feedback and were asked to read and think about it for $1 \mathrm{~min}$. The first eight feedback screens were preceded by an instruction to adopt a self- 


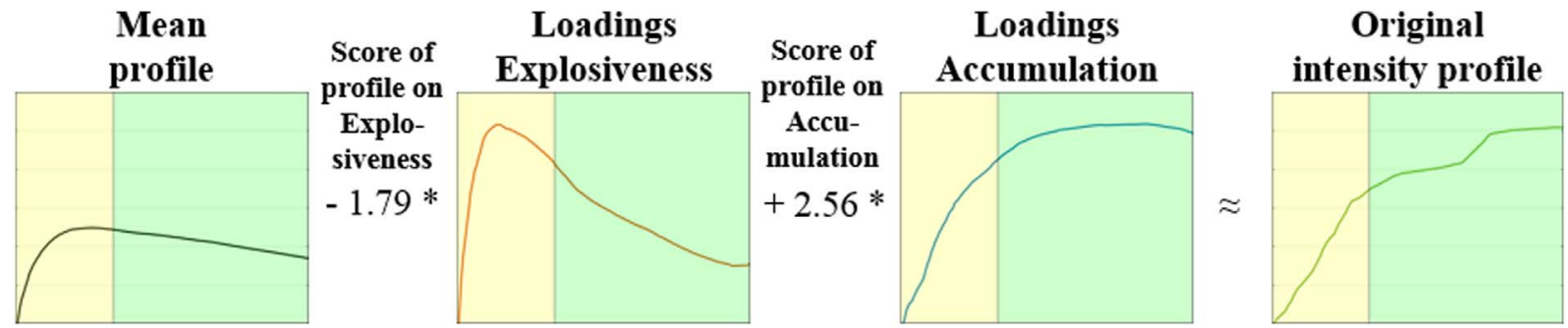

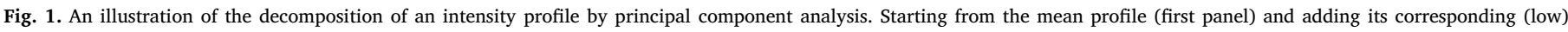

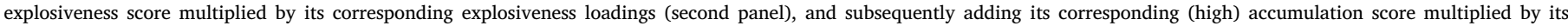

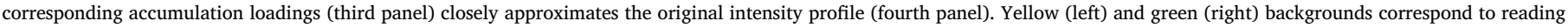
and thinking about the feedback, respectively. (For interpretation of the references to color in this figure legend, the reader is referred to the web version of this article.)

distanced (or self-immersed) perspective, and the next eight feedback screens were preceded by an instruction to adopt a self-immersed (or self-distanced) perspective. The order of the instructions was counterbalanced across participants. The self-distancing instruction requested participants to "read and think about the feedback while adopting a detached attitude with regard to this feedback, as if you were an impartial observer, a scientist who analyses the feedback objectively", whereas the self-immersed instruction required them to "read and think about the feedback while concentrating on what it implies for you as a person, on what are the specific feelings you are experiencing subjectively at this feedback". Similar instructions have been used successfully in previous research to regulate subjective emotional experience as well as activity in the central and peripheral nervous system (Gruber, Harvey, \& Johnson, 2009; Kross, Ayduk, \& Mischel, 2005; Ochsner et al., 2004; Ray, Wilhelm, \& Gross, 2008). Immediately after having thought about the feedback, participants had to report on changes in negative affect that occurred while reading and thinking about it using the same intensity profile tracking approach as in Study 1 of Résibois, Kalokerinos, et al. (2017). In early research using an intensity profile tracking approach (Sonnemans \& Frijda, 1994, 1995; Verduyn et al., 2009; Verduyn, Van Mechelen, \& Frederix, 2012), the time separating emotional experience from reporting on that experience was much longer. By requesting participants to report on their emotional change using the emotion intensity profile tracking approach immediately after their emotional experience, we minimize the probability of self-report reflecting lay theories rather than actual emotional experiences (Kahneman, Krueger, Schkade, Schwarz, \& Stone, 2004). Each trial ended with a 15-second relaxation period.

In Phase 4 (duration: $10 \mathrm{~min}$ ), a funnelled debriefing was used to detect participants' suspicion about the cover story. As in previous studies using manipulated social feedback (Nummenmaa \& Niemi, 2004; Rigoni, Braem, Pourtois, \& Brass, 2016; Soederberg Miller \& West, 2009), a number of participants (i.e., 20 out of the 70 participants) reported minor or strong suspicion that the feedback was manipulated. Critically, however, although participants who did not believe the cover story experienced lower levels of explosiveness $(p=0.09)$ and accumulation $(p=0.006)$, rerunning the analyses without the disbelievers (resulting in $n=50$ ) did not alter any of the conclusions we report (regarding the impact of perspective taking on emotion dynamics and the moderation of this impact by depression severity). Finally, a full debriefing followed, including an explanation of the real purpose of the study.

\section{Data analysis}

\subsection{Intensity profile features}

We used the same procedure as Résibois, Kalokerinos, et al. (2017; see also Verduyn, Van Mechelen, \& Frederix, 2012; Verduyn et al., 2009 ) to quantify the amount of explosiveness and accumulation in the obtained 560 emotion intensity profiles reflecting changes in negative affect while reading and thinking about negative feedback. More specifically, the 780 time points of each of the 560 negative emotion intensity profiles were transformed into a function using linear interpolation - as implemented in Matlab R2015b's interp1 function (v. 8.6.0.267246 - R2015b, The MathWorks Inc., 2015) - and subsequently converted into intensity values at 150 equally distant time points. Next, the resulting $560 \times 150$ profile by time point matrix was subjected to a Principal Component Analysis (PCA), with the profiles taking the role of the objects (experimental units) and the time points the role of the variables. The PCA in question was a PCA of the covariances followed by a VARIMAX rotation - as implemented in SPSS (v. 23, IBM Corp, 2015) - to ease the substantive interpretation of the component solution (For additional information on PCA applied to functional data, see, e.g., Ramsay \& Silverman, 2005). This PCA resulted in the decomposition of the profile by time point data into component loadings of the time points and component scores of the profiles. The loadings for a component can be plotted as a function over time and can be read as a dynamic feature underlying profile variability. The scores for a component can be conceived as weights that reflect the degree to which each intensity profile is characterized by the dynamic feature associated with the component in question. Subsequently, each intensity profile can be reconstructed as the mean profile plus a weighted sum of dynamic features (i.e., a sum of the loadings for each component weighted or multiplied by the corresponding scores of the intensity profile under study). A graphical representation of this decomposition process is shown in Fig. 1.

\subsection{Effect of perspective taking on emotion explosiveness and accumulation}

Multilevel analysis was used to model the effect of the manipulation on the temporal unfolding of emotions. In particular, the two PCA component scores (i.e., explosiveness and accumulation) were predicted by a dummy predictor (self-immersion equal to 0 and self-distancing equal to 1) at Level 1 of the model. The intercept and slope were allowed to vary randomly across participants (see Supplementary Information for model equations).

\subsection{Moderation of the perspective taking manipulation by depression severity}

We first examined the main effect of depression severity by adding the grand-mean centered CES-D score as a predictor of explosiveness and accumulation at Level 2 of the model, in addition to the dummy predictor reflecting the experimental manipulation at Level 1 . Critically, we then examined the possible moderation of our self-distancing manipulation by further adding a cross-level interaction between depression severity and the dummy predictor that corresponds to the experimental manipulation (see Supplementary Information for model equations). 

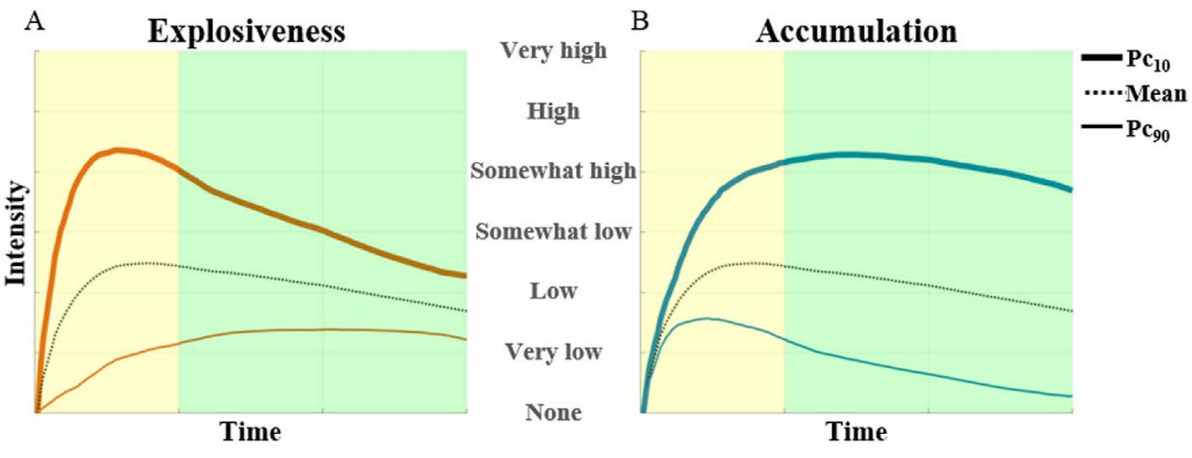

Fig. 2. Results of principal component analysis ran on all negative trials. Reconstructed profiles taking a high (90th percentile), average, or low (10th percentile) score on the component of interest and an average score on the other component, presented according to the order of their peaks in the temporal process. Yellow (left) and green (right) backgrounds correspond to the periods when reading and thinking about the feedback, respectively. Left panel (A): High and low scoring profiles show an explosive and gentle start, respectively (explaining $33.46 \%$ of profile variability). Right panel (B): High and low scoring profiles show emotion intensification and recovery, respectively (explaining $59.16 \%$ of profile variability). (For interpretation of the references to color in this figure legend, the reader is referred to the web version of this article.)

\section{Results}

\subsection{Emotion intensity profile features}

Formal criteria (Jolliffe, 2002) to decide upon the number of components were not univocal, with the optimal number ranging from 1 or 2 (according to the scree plot based on the first nine eigenvalues: $2.27 \mathrm{e}+06$, $2.02 e+05,8.93 e+04,4.06 e+04,2.13 e+04,1.17 e+04,7.62 e+03$, and $6.36 \mathrm{e}+03$ and $3.86 \mathrm{e}+03$ ) to 4 (according to a parallel analysis ran using the paran package (v. 1.5.1, Dinno, 2012) developed for R) or 5 (according to Kaiser's rule adapted to PCA analysis on the covariance matrix). We decided to retain a (VARIMAX rotated) two-component solution. This solution was preferred over a 1-component solution as the component derived from a 1-component solution mainly reflects the overall intensity level of the profile. Thus, this solution does not allow us to examine the impact of self-distancing on truly time-dynamic features of emotion unfolding. Moreover, we preferred a 2-component solution over a solution with more than two components, because (a) a two-component solution was also found in an earlier experimental study using the intensity profile tracking approach (Résibois, Kalokerinos, et al., 2017), and (b) the amounts of variance explained by a one-component solution (85.1\%) as well as a two-component solution (92.6\%) already exceed the recommended threshold of 80-90\% (Jolliffe, 2002).

Similar to earlier studies using the intensity profile tracking approach (Résibois, Kalokerinos, et al., 2017; Verduyn et al., 2009; Verduyn, Van Mechelen, \& Frederix, 2012), intensity profiles scoring high (90th percentile), average, or low (10th percentile) on one component while taking an average score on the other component were reconstructed to interpret the two-component solution (see Fig. 2). The first component (explaining 33.5\% of the variance after VARIMAX rotation) reflects emotion explosiveness as it comes to the fore during the period of emotion onset, with high and low explosiveness scores reflecting a steep and smooth start, respectively. The second component (explaining $59.2 \%$ of the variance after VARIMAX rotation) reflects emotion accumulation as it comes to the fore during the period of emotion offset, with high and low accumulation scores showing emotion intensification or recovery, respectively. In sum, similar to previous studies (Résibois, Kalokerinos, et al., 2017; Verduyn et al., 2009; Verduyn, Van Mechelen, \& Frederix, 2012), we found that emotion explosiveness and accumulation are the two main dynamic features underlying variability in negative emotion intensity profiles.

\subsection{Effect of perspective taking on emotion explosiveness and accumulation}

As expected, adopting a self-distanced (vs. self-immersed) perspective was found to lead to lower levels of explosiveness $(B=-0.48$, $\beta^{2}=-0.35, t(489)=-5.51, p<0.001,95 \%$ confidence interval

\footnotetext{
${ }^{2} \beta$ is the within-person standardized $B$ value computed following the recommendation of Schuurman, Ferrer, de Boer-Sonnenschein, and Hamaker (2016) and is added as a measure of effect size.
}

[CI] $[-0.66,-0.31])$ and accumulation $(B=-0.33, \beta=-0.26, t$ $(489)=-3.65, p<0.001,95 \%$ CI $[-0.51,-0.15])$. We additionally explored the possible role of trial number and order of the condition. Condition order was not found to be significantly related to explosiveness or accumulation ( $p s>0.13$ ). In contrast, trial number was marginally significantly and negatively associated with emotion explosiveness $(B=-0.02, t(488)=-1.70, p=0.09)$ and accumulation $(B=-0.02, t(488)=-1.88, p=0.06)$, suggesting that participants somewhat habituated to the social feedback as the study progressed. Importantly, however, controlling for trial number and order of the condition did not influence the impact of perspective taking on both features. In contrast to our hypothesis, the corresponding effect size of our manipulation was slightly higher (rather than lower) when predicting explosiveness than accumulation.

\subsection{Moderation of the perspective taking manipulation by depression severity}

Depression severity was not related to emotion explosiveness $(B=0.08, \beta=0.06, t(68)=0.33, p=0.74,95 \%$ CI $[-0.39,0.54])$. Yet, it appeared to have a positive association with emotion accumulation as reflected by a marginally significant main-effect $(B=0.46$, $\beta=0.45, t(68)=1.90, p=0.06,95 \%$ CI $[-0.02,0.95])$.

More important, depression severity moderated, as hypothesized, the impact of perspective taking on emotion accumulation as reflected by a significant cross-level interaction $(B=-0.54, \beta=-0.20, t$ $(488)=-2.18, p=0.03$, 95\% CI $[-1.03,-0.05]$, see Fig. 3). Controlling for trial number and condition order did not alter this effect. In contrast to the impact of perspective taking on emotion accumulation, the effect of the manipulation on emotion explosiveness was not moderated by depression severity $(B=0.17, \beta=0.05, t(488)=0.70$, $p=0.48,95 \%$ CI $[-0.31,0.66]$, see Fig. 3 ).

To better understand the significant cross-level interaction, we first tested simple main effects examining the impact of perspective taking on emotion accumulation for people scoring high (1SD above the mean), average, and low (1SD below the mean) on depression severity. For people scoring high $(B=-0.53, \beta=-0.77, t(488)=-4.19, p \leq 0.001,95 \%$ CI $[-0.78,-0.28])$ and average $(B=-0.33, \beta=-0.49, t(488)$ $=-3.75, p \leq 0.001,95 \%$ CI $[-0.51,-0.16])$ on depression severity, adopting a self-distanced (vs. self-immersed) perspective leads to lower levels of accumulation. For people scoring low on depression severity, however, perspective taking was not found to be related to accumulation $(B=-0.14, \beta=-0.20, t(488)=-1.11, p=0.27,95 \%$ CI $[-0.39$, $0.11])$. Second, we tested simple main effects examining the relationship between depression severity and emotion accumulation when adopting a self-immersed or self-distanced perspective. When participants adopted a self-immersed perspective, depression severity was positively related to emotion accumulation $(B=0.76, \beta=0.74, t(68)=2.72, p=0.008,95 \%$ CI $[0.20,1.32])$, whereas this was no longer the case when participants adopted a self-distanced perspective $(B=0.22, \beta=0.21, t(68)=0.82$, $p=0.42,95 \%$ CI $[-0.32,0.76])$. 


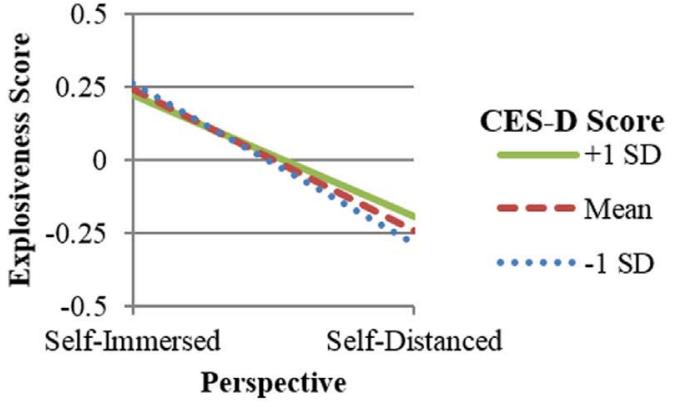

\section{Discussion}

The aim of the present study was to acquire a better understanding of the impact of self-distancing on emotion unfolding. A first key finding pertains to the general relationship between perspective taking and emotion unfolding. Replicating previous research, we found that adopting a self-distanced (vs. self-immersed) perspective led to lower levels of emotion intensity (Ayduk \& Kross, 2010). Critically extending previous research, we found that perspective taking influences emotion intensity in both the initial and the later stage of emotion unfolding (as reflected by its impact on emotion explosiveness and accumulation, respectively). In contrast to our hypotheses, the effect of our manipulation was not more outspoken for accumulation than for explosiveness. This might be due to our perspective taking instruction already appearing before the emotion-eliciting stimulus, whereas, in real life settings, perspective taking perhaps only spontaneously takes place sometime after the emotion-eliciting event occurred. Consistent with this interpretation, in a recent study on emotion regulation in daily life, it was found that spontaneous perspective taking typically occurs late during the emotional episode (Kalokerinos et al., 2017).

The second key finding of the present study is that the relationship between perspective taking and emotion accumulation (but not emotion explosiveness) is moderated by depression severity. The nature of this moderation can be understood in two different ways. On the one hand, one may argue that participants high in depression severity benefit more from self-distancing than participants suffering from less severe levels of depression. This conclusion is consistent with earlier research showing that self-distancing is especially effective for people scoring high on depression severity (Kross \& Ayduk, 2009) and extends them by pinpointing that this moderating effect is specific to emotion accumulation.

On the other hand, one may argue that depression severity specifically leads to higher levels of emotion accumulation only when adopting a self-immersed perspective. This interpretation is consistent with diathesis-stress theories, according to which vulnerability to depression is especially manifested when dealing inappropriately with environmental stressors (Power \& Dalgleish, 2007), and extends it by showing that this manifestation is specifically seen at the level of emotion accumulation. Conversely, self-distancing may operate as a protective factor preventing negative emotions to accumulate.

Studies on emotion dynamics still being in their early stage, several challenges remain for future research. First, the present findings highlight the moderation of the effect of perspective taking by depression severity in a university student population differing in levels of depression severity according to the CES-D rather than a clinical population. Although self-distancing was found to also be beneficial for people with a depressive disorder (Kross et al., 2012), future research assessing the impact of adopting a self-distanced (vs. self-immersed) perspective on emotion dynamics in participants suffering from clinical depression is necessary to corroborate the present findings. Second, it cannot be ruled out that memory biases or participants' expectations of how emotions unfold over time (i.e., lay theories) may still have slightly affected the emotion intensity profiles. However, the fact that participants reported on their emotion dynamics immediately after the emotional experience, and that emotion explosiveness and accumulation were found to be associated with distinctive neural correlates in a study using a highly similar design (Résibois, Verduyn, et al., 2017), argues against this possibility. Yet, to fully overcome this limitation, one could consider having participants report on changes in their emotional experience online (e.g., by moving a joystick). However, we did not use this alternative approach as adopting a self-distanced (vs self-immersed) perspective while simultaneously having to report on changes in emotion intensity over time online might have been too much of a burden for the participants. Third, future studies might benefit from a baseline assessment to better separate baseline individual differences from differences in explosiveness. Fourth, future research is needed to examine the specific processes that underlie the interaction between depression severity and perspective taking on emotion accumulation. Fifth, although this paper extends our knowledge on the effect of perspective taking on emotion intensity profile features, future studies are necessary to explore whether this effect is specific to perspective taking or whether other strategies known to downregulate negative emotion, such as distraction (Gross, 2015), have similar consequences on emotion unfolding. Finally, taking into account that adopting a self-distanced (vs. self-immersed) perspective has been shown to reduce both negative and positive emotions (Verduyn, Van Mechelen, Kross, et al., 2012), future work is necessary to explore whether the present results hold for positive emotions as well.

\section{Acknowledgements}

The research leading to the results reported in this paper was supported in part by the Research Fund of KU Leuven [GOA/15/003] and by the Interuniversity Attraction Poles programme financed by the Belgian government [IAP/P7/06]. Philippe Verduyn is supported as a postdoctoral fellow of the Research Foundation - Flanders (FWO).

\section{Appendix A. Supplementary Information}

Supplementary data to this article can be found online at https:// doi.org/10.1016/j.paid.2017.11.018.

\section{References}

Ayduk, Ö., \& Kross, E. (2008). Enhancing the pace of recovery: Self-distanced analysis of negative experiences reduces blood pressure reactivity. Psychological Science, 19(3), 229-231. http://dx.doi.org/10.1111/j.1467-9280.2008.02073.x.

Ayduk, Ö., \& Kross, E. (2010). Analyzing negative experiences without ruminating: The role of self-distancing in enabling adaptive self-reflection. Social and Personality Psychology Compass, 4(10), 841-854. http://dx.doi.org/10.1111/j.1751-9004.2010. 00301.x.

Bushman, B. J., \& Baumeister, R. F. (1998). Threatened egotism, narcissism, self-esteem, and direct and displaced aggression: Does self-love or self-hate lead to violence? Journal of Personality and Social Psychology, 75(1), 219-229. http://dx.doi.org/10. 1037/0022-3514.75.1.219.

Davidson, R. J. (1998). Affective style and affective disorders: Perspectives from affective neuroscience. Cognition \& Emotion, 12(3), 307-330. http://dx.doi.org/10.1080/ 026999398379628.

Denny, B. T., \& Ochsner, K. N. (2014). Behavioral effects of longitudinal training in 
cognitive reappraisal. Emotion, 14(2), 425-433. http://dx.doi.org/10.1037/ a0035276.

Dinno, A. (2012). paran: Horn's test of principal components/factors, v. 1.5.1.

Eisenberger, N. I., Inagaki, T. K., Muscatell, K. A., Byrne Haltom, K. E., \& Leary, M. R. (2011). The neural sociometer: Brain mechanisms underlying state self-esteem. Journal of Cognitive Neuroscience, 23(11), 3448-3455. http://dx.doi.org/10.1162/ jocn_a_00027.

Faul, F., Erdfelder, E., Lang, A.-G., \& Buchner, A. (2007). G*Power 3: A flexible statistical power analysis program for the social, behavioral, and biomedical sciences. Behavior Research Methods, 39(2), 175-191. http://dx.doi.org/10.3758/BF03193146.

Frijda, N. H. (2007). The laws of emotion. Mahwah, NJ, US: Lawrence Erlbaum.

Gross, J. J. (2015). Emotion regulation: Current status and future prospects. Psychological Inquiry, 26(1), 1-26. http://dx.doi.org/10.1080/1047840X.2014.940781.

Gruber, J., Harvey, A. G., \& Johnson, S. L. (2009). Reflective and ruminative processing of positive emotional memories in bipolar disorder and healthy controls. Behaviour Research and Therapy, 47(8), 697-704. http://dx.doi.org/10.1016/j.brat.2009.05. 005.

Houben, M., Van Den Noortgate, W., \& Kuppens, P. (2015). The relation between shortterm emotion dynamics and psychological well-being: A meta-analysis. Psychological Bulletin, 141(4), 901-930. http://dx.doi.org/10.1037/a0038822.

IBM Corp (2015). IBM SPSS statistics for Windows version 23.0.0.2. Armonk, NY, USA: IBM Corp.

Jolliffe, I. (2002). Principal component analysis, second edition (2nd ed.). New York, NY, USA: Springer.

Kahneman, D., Krueger, A., Schkade, D. A., Schwarz, N., \& Stone, A. A. (2004). A survey method for characterizing daily life experience: The day reconstruction method. Science, 306(5702), 1776-1780. http://dx.doi.org/10.1126/science.1103572.

Kalokerinos, E. K., Résibois, M., Verduyn, P., \& Kuppens, P. (2017). The temporal deployment of emotion regulation strategies during negative emotional episodes. Emotion, 17(3), 450-458. http://dx.doi.org/10.1037/emo0000248.

Koole, S. L. (2009). The psychology of emotion regulation: An integrative review. Cognition \& Emotion, 23(1), 4-41. http://dx.doi.org/10.1080/02699930802619031.

Kross, E., \& Ayduk, Ö. (2008). Facilitating adaptive emotional analysis: Distinguishing distanced-analysis of depressive experiences from immersed-analysis and distraction. Personality and Social Psychology Bulletin, 34(7), 924-938. http://dx.doi.org/10 $1177 / 0146167208315938$.

Kross, E., \& Ayduk, Ö. (2009). Boundary conditions and buffering effects: Does depressive symptomology moderate the effectiveness of self-distancing for facilitating adaptive emotional analysis? Journal of Research in Personality, 43(5), 923-927. http://dx.doi. org/10.1016/j.jrp.2009.04.004.

Kross, E., Ayduk, Ö., \& Mischel, W. (2005). When asking "why" does not hurt: Distinguishing rumination from reflective processing of negative emotions. Psychological Science, 16(9), 709-715. http://dx.doi.org/10.1111/j.1467-9280.2005. 01600.x.

Kross, E., Gard, D., Deldin, P., Clifton, J., \& Ayduk, Ö. (2012). "Asking why” from a distance: Its cognitive and emotional consequences for people with major depressive disorder. Journal of Abnormal Psychology, 121(3), 559-569. http://dx.doi.org/10. $1037 / \mathrm{a} 0028808$.

Kuppens, P., \& Verduyn, P. (2015). Looking at emotion regulation through the window of emotion dynamics. Psychological Inquiry, 26(1), 72-79. http://dx.doi.org/10.1080/ 1047840X.2015.960505.

Nigro, G., \& Neisser, U. (1983). Point of view in personal memories. Cognitive Psychology, 15(4), 467-482. http://dx.doi.org/10.1016/0010-0285(83)90016-6.

Nolen-Hoeksema, S., Wisco, B. E., \& Lyubomirsky, S. (2008). Rethinking rumination. Perspectives on Psychological Science, 3(5), 400-424. http://dx.doi.org/10.1111/j. 1745-6924.2008.00088.x.

Nummenmaa, L., \& Niemi, P. (2004). Inducing affective states with success-failure manipulations: A meta-analysis. Emotion, 4(2), 207-214. http://dx.doi.org/10.1037/ 1528-3542.4.2.207.

Ochsner, K. N., Ray, R. D., Cooper, J. C., Robertson, E. R., Chopra, S., Gabrieli, J., \& Gross, J. J. (2004). For better or for worse: Neural systems supporting the cognitive downand up-regulation of negative emotion. NeuroImage, 23(2), 483-499. http://dx.doi. org/10.1016/j.neuroimage.2004.06.030.

Papageorgiou, C., \& Wells, A. (2001). Metacognitive beliefs about rumination in recurrent major depression. Cognitive and Behavioral Practice, 8(2), 160-164. http://dx.doi.org/ 10.1016/S1077-7229(01)80021-3.

Penner, L. A., Guevarra, D. A., Harper, F. W. K., Taub, J., Phipps, S., Albrecht, T. L., \& Kross, E. (2016). Self-distancing buffers high trait anxious pediatric cancer caregivers against short- and longer-term distress. Clinical Psychological Science, 4(4), 629-640. http://dx.doi.org/10.1177/2167702615602864.

Power, M., \& Dalgleish, T. (2007). Cognition and emotion: From order to disorder (2nd ed.). Hove, UK: Psychology Presshttp://dx.doi.org/10.4324/9780203934487.

Radloff, L. S. (1977). The CES-D scale: A self-report depression scale for research in the general population. Applied Psychological Measurement, 1(3), 385-401. http://dx.doi. org/10.1177/014662167700100306.

Ramsay, J. O., \& Silverman, B. W. (2005). Functional data analysis (2nd ed.). New York, NY: Springer-Verlag.

Ray, R. D., Wilhelm, F. H., \& Gross, J. J. (2008). All in the mind's eye? Anger rumination and reappraisal. Journal of Personality and Social Psychology, 94(1), 133-145. http:// dx.doi.org/10.1037/0022-3514.94.1.133.

Résibois, M., Kalokerinos, E. K., Verleysen, G., Kuppens, P., Van Mechelen, I., Fossati, P., \& Verduyn, P. (2017). The relation between rumination and temporal features of emotion intensity. Cognition \& Emotion. Advance online publication https://doi.org/ 10.1080/02699931.2017.1298993.

Résibois, M., Verduyn, P., Delaveau, P., Rotgé, J.-Y., Kuppens, P., Van Mechelen, I., \& Fossati, P. (2017). The neural basis of emotions varies over time: Different regions go with onset- and offset-bound processes underlying emotion intensity. Social Cognitive and Affective Neuroscience, 12(8), 1261-1271. http://dx.doi.org/10.1093/scan/ nsx051.

Rigoni, D., Braem, S., Pourtois, G., \& Brass, M. (2016). Fake feedback on pain tolerance impacts proactive versus reactive control strategies. Consciousness and Cognition, 42 366-373. http://dx.doi.org/10.1016/j.concog.2016.04.015.

Robinson, J. A., \& Swanson, K. L. (1993). Field and observer modes of remembering. Memory, 1(3), 169-184. http://dx.doi.org/10.1080/09658219308258230.

Schuurman, N. K., Ferrer, E., de Boer-Sonnenschein, M., \& Hamaker, E. L. (2016). How to compare cross-lagged associations in a multilevel autoregressive model. Psychological Methods, 21(2), 206-221. http://dx.doi.org/10.1037/met0000062.

Soederberg Miller, L. M., \& West, R. L. (2009). The effects of age, control beliefs, and feedback on self-regulation of reading and problem solving. Experimental Aging Research, 36(1), 40-63. http://dx.doi.org/10.1080/03610730903418380.

Sonnemans, J., \& Frijda, N. H. (1994). The structure of subjective emotional intensity. Cognition \& Emotion, 8(4), 329-350. http://dx.doi.org/10.1080/ 02699939408408945.

Sonnemans, J., \& Frijda, N. H. (1995). The determinants of subjective emotional intensity. Cognition \& Emotion, 9(5), 483-506. http://dx.doi.org/10.1080/ 02699939508408977.

The MathWorks Inc. (2015). MATLAB version 8.6.0.267246 (R2015b). (Natick, MA, USA).

Verduyn, P., Van Mechelen, I., \& Frederix, E. (2012). Determinants of the shape of emotion intensity profiles. Cognition \& Emotion, 26(8), 1486-1495. http://dx.doi.org/ $10.1080 / 02699931.2012 .662152$.

Verduyn, P., Van Mechelen, I., Kross, E., Chezzi, C., \& Van Bever, F. (2012). The relationship between self-distancing and the duration of negative and positive emotional experiences in daily life. Emotion, 12(6), 1248-1263. http://dx.doi.org/10. 1037/a0028289.

Verduyn, P., Van Mechelen, I., Tuerlinckx, F., Meers, K., \& Van Coillie, H. (2009). Intensity profiles of emotional experience over time. Cognition \& Emotion, 23(7), 1427-1443. http://dx.doi.org/10.1080/02699930902949031.

Webb, T. L., Miles, E., \& Sheeran, P. (2012). Dealing with feeling: A meta-analysis of the effectiveness of strategies derived from the process model of emotion regulation. Psychological Bulletin, 138(4), 775-808. http://dx.doi.org/10.1037/a0027600.

Wilson, T. D., \& Gilbert, D. T. (2008). Explaining away: A model of affective adaptation. Psychological Science, 3(5), 370-386. http://dx.doi.org/10.1111/j.1745-6924.2008. 00085.x. 